\title{
Evaluating Predicting Aerosol PM 10 Concentrations with the WRF-Chem Model, in Lima, in February 2018
}

\author{
Odón Sánchez-Ccoyllo ${ }^{1}$, Alan Llacza ${ }^{2}$, Paula Castesana ${ }^{3}$ \\ ${ }^{1}$ Universidad Nacional Tecnológica de Lima Sur \\ Av. Bolivar S/N, sector 3, grupo 1, mz A, sublote 3, Villa El Salvador, Lima, Peru \\ osanchez@untels.edu.pe \\ ${ }^{2}$ National Meteorology and Hydrology Service (SENAMHI), Lima, Peru \\ allacza@senamhi.gob.pe \\ ${ }^{3}$ Consejo Nacional de Investigaciones Científicas y Técnicas (CONICET), Buenos Aires, Argentina \\ pcastesana@gmail.com
}

\begin{abstract}
Particulate matter with aerodynamic diameters equal to or less than $10 \mu \mathrm{m}\left(\mathrm{PM}_{10}\right)$ concentration in the Metropolitan Area of Lima - Callao (MALC) frequently exceeds the daily Peruvian National Ambient Air Quality Standard for PM $10\left(100 \mu \mathrm{g} / \mathrm{m}^{3}\right)$ and the daily World Health Organization Guideline $\left(50 \mu \mathrm{g} / \mathrm{m}^{3}\right)$. The aim of this study was to simulate the hourly $\mathrm{PM}_{10}$ concentration and evaluate the model performance. The prediction of $\mathrm{PM}_{10}$ concentration was done using the "Weather Research and Forecasting Model Coupled with Chemistry" (WRF-Chem) air pollution modeling system. Therefore, in this study, WRF-Chem (version 4.0) was applied to simulate $\mathrm{PM}_{10}$ concentrations from January 30, 2018 to February 28, 2018. The first 2 days were used as spin-up in order to minimize the influence of the initial conditions with a 5-km-by-5-km grid over MALC. This $\mathrm{PM}_{10}$ concentrations prediction was validated against ground-based observations. For validating the aerosol $\mathrm{PM}_{10}$ simulations, hourly $\mathrm{PM}_{10}$ in-situ measurements from two traffic air quality monitoring stations named Ate and Puente Piedra in the MALC were used. The results showed that the prediction of PM PM $_{10}$ mass concentration at the (Ate and Puente Piedra) traffic air quality monitoring stations reasonably captures the observed PM $\mathrm{PM}_{10}$ temporal. However, $\mathrm{PM}_{10}$ concentrations estimated were under-estimated by the WRF-Chem model.
\end{abstract}

Keywords: Atmospheric modeling, air quality, chemistry, air pollution

\section{Introduction}

Efficient air pollution simulations are necessary because they could help policymakers to develop air quality regulation and decide on emission reduction [1]. In this study, a coupled on-line modeling system, the Weather Research and Forecasting model coupled with chemistry (WRF-Chem) [2] was used to simulate the hourly PM $_{10}$ mass concentration. WRF-Chem is a regional air pollution model [2]. The WRF-Chem model is a completely coupled online meteorologychemistry in which the same diffusion, advection, and convection schemes were used for the $\mathrm{PM}_{10}$ mass concentration prediction [3]. The WRF-Chem dynamically manages different processes such as photolysis, transport, gas-phase chemical mechanism, plume rise, aerosol chemistry, wet and dry deposition, anthropogenic, aerosol radiation, and biogenic emission, etc. [2]. Detailed descriptions of the WRF-Chem model can be found on the website (https://ruc.noaa.gov/wrf/wrf-chem/2. The WRF-Chem model performance was evaluated by many researchers in the world, for example $[4,5,6]$. However, there are only few studies about numerical estimation of air quality in the MALC for example [4]. This study aims to predict the hourly $\mathrm{PM}_{10}$ concentration and evaluate the WRF-Chem model performance in the MALC in February 2018.

\section{Methods}

\subsection{Study Area}

In this study, we have chosen two traffic air quality monitoring stations named Ate (A) $\left(76^{\circ} 55^{\prime} 7^{\prime \prime} \mathrm{W}, 12^{\circ} 1^{\prime} 34^{\prime \prime} \mathrm{S}\right)$ and Puente Piedra (P) $\left(77^{\circ} 4^{\prime} 26.88^{\prime \prime} \mathrm{W}, 11^{\circ} 51^{\prime} 47.7^{\prime \prime} \mathrm{S}\right)$ (Fig. 1) in order to evaluate predicting $\mathrm{PM}_{10}$ concentration in the MALC. Heavy vehicular traffic, population, and industries are concentrated in the Lima districts of Ate and Puente Piedra. They are places where $\mathrm{PM}_{10}$ concentrations air pollution problems are severe. The hourly near-surface $\mathrm{PM}_{10}$ concentration observation 
for Ate's and Puente Piedra's air quality monitoring stations was obtained from the National Service of Meteorology and Hydrology of Peru (https://web2.senamhi.gob.pe/?p=calidad-de-aire).

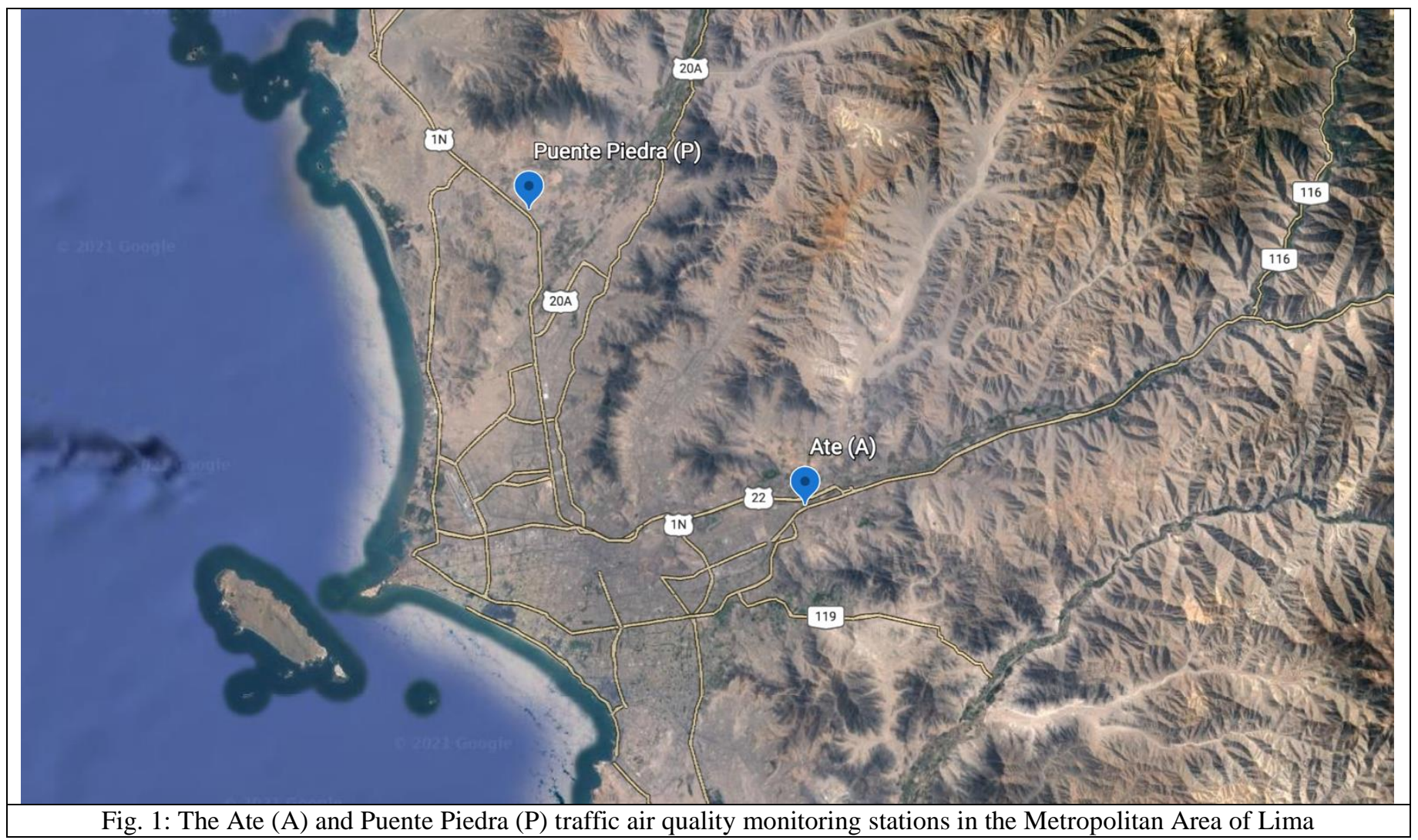

\subsection{WRF-Chem Modeling Setup}

The WRF-Chem (version 4.0) used to simulate $\mathrm{PM}_{10}$ mass concentrations in the MALC. In this study, the gas-phase chemical reactions were calculated using the RADM2 (Regional Acid Deposition Model, version 2) chemical mechanism. It is a reduced gas-phase photoxidation mechanism [5]. Included in the "RADM2 are: i) three classes of alkanes; ii) aromatic chemistry; iii) two alkenes classes; iv) ketones and dicarbonysls are distinct classes; v) isoprene is an explicit species; and peroxy radical reactions" [6]. The aerosol chemical reactions were calculated using the MADE-SORGAM (Modal Aerosol Dynamics Model for Europe-Secondary Organic Aerosol Model) model. It is a modal scheme that expresses three log-normal distribute modes to predict particle size distribution: i) the Aitken mode $(<0.1 \mu$ m diameter $)$; ii) the accumulation mode ( 0.1 $2 \mu \mathrm{m}$ diameter); and, iii) the coarse mode ( 2-10 $\mu$ m diameter) [5].

The Operational Global Analysis "National Centers for Environmental Prediction" (NCEP) - Final Analysis (FNL) with spatial resolution of 0.25-degree-by-0.25-degree grids every six hours (00, 06, 12 and 18 UTC) was used for the initial and physical conditions for WRF simulations (https://rda.ucar.edu/datasets/ds084.1/). The geo-physical parameters such as orography was taken from ASTER GDEM (Advanced Spaceborne Thermal Emission and Reflection Radiometer, Global Digital Elevation Model), and land use was taken from USGS (U.S. Geological Survey) datasets. The anthropogenic emissions of air contamination in a $5 \mathrm{~km}$ horizontal resolution grid domain [4] were based on the emission vehicular model [7]. This model considers that air atmospheric emission only comes from on-road vehicles [7]. Finally, WRF-chem model output was gotten on hourly $\mathrm{PM}_{10}$ concentrations. 


\section{Results and Discussion}

WRF-Chem results at the lowest model layer for the Ate and Puente Piedra traffic air quality monitoring stations with with in-situ $\mathrm{PM}_{10}$ data were extracted, and, for these stations, statistical metrics to provide a measure model's error were calculated. Statistical parameters were implemented to evaluate the effectiveness of $\mathrm{PM}_{10}$ mass concentrations predictions. predictions. That parameters used were Mean Bias (MB), Mean Normalized Bias (MNB), Mean Gross Error (MGE), Mean Mean Normalized Gross Error (MNGE), and Root Mean Square Error (RMSE) as metric indicators to evaluate the WRFChem model performance. These indices are described as shown in Eqs. (1)- (5) [8]:

$$
\begin{gathered}
M B=\frac{1}{N} \sum_{i=1}^{N}\left(M_{i}-O_{i}\right) \\
M N B=\frac{\sum_{i=1}^{N}\left(M_{i}-O_{i}\right)}{\sum_{i=1}^{N} O_{i}} \\
M G E=\frac{1}{N} \sum_{i=1}^{N}\left|M_{i}-O_{i}\right| \\
M N G E=\frac{\sum_{i=1}^{N}\left|M_{i}-O_{i}\right|}{\sum_{i=1}^{N} O_{i}} \\
\text { RMSE }=\left[\frac{1}{N} \sum_{i=1}^{N}\left(M_{i}-O_{i}\right)^{2}\right]^{1 / 2}
\end{gathered}
$$

Where $\mathrm{N}$ is the total number of data pairs; $\mathrm{M}_{\mathrm{i}}$ is the predicted $\mathrm{PM}_{10}$ concentrations, and $\mathrm{O}_{\mathrm{i}}$ is the observed $\mathrm{PM}_{10}$ concentrations. The results of these metric indices for $\mathrm{PM}_{10}$ mass concentrations are presented (Table 1). The MB (-67.1 $\left.\mu \mathrm{g} / \mathrm{m}^{3}\right)$ and MNB (-62.2\%) for Ate and the MB (-63.3 $\left.\mu \mathrm{g} / \mathrm{m}^{3}\right)$ and MNB (-57.5\%) for Puente Piedra were negative indicating that the $\mathrm{PM}_{10}$ total mass was under-predicted by the WRF-Chem model. The MGE $\left(61.7 \mu \mathrm{g} / \mathrm{m}^{3}\right)$, MNGE $(62.4 \%$,), and $\operatorname{RMSE}\left(84.9 \mu \mathrm{g} / \mathrm{m}^{3}\right)$ for Ate and the MGE $\left(64.2 \mu \mathrm{g} / \mathrm{m}^{3}\right)$, MNGE $\left(55.6 \%\right.$,), and RMSE $\left(77.6 \mu \mathrm{g} / \mathrm{m}^{3}\right)$ for Puente Piedra indicate that the WRF-Chem model performed badly. The $\mathrm{PM}_{10}$ concentrations estimated $(40.5 \pm 33.8)$ for Ate and $(46.4 \pm 27.4)$ for Puente Piedra were under-estimated by the WRF-Chem model, because average and standard deviation of PM 10 observed were $107.9 \pm 61.1$ for Ate and $110.2 \pm 47.4$ for Puente Piedra respectively. The $\mathrm{PM}_{10}$ predicted reasonably captured the temporal variation of the $\mathrm{PM}_{10}$ observed (figure not shown).

Table 1: WRF-Chem model evaluation for $\mathrm{PM}_{10}$ mass concentrations at the Ate and Puente Piedra traffic air quality monitoring stations in Lima

\begin{tabular}{|c|c|c|}
\hline Statistical measure & Ate traffic air quality monitoring station & $\begin{array}{l}\text { Puente Piedra traffic air quality } \\
\text { monitoring station }\end{array}$ \\
\hline PM $_{10}$ observed & $107.9 \pm 61.1$ & $110.2 \pm 47.4$ \\
\hline $\mathrm{PM}_{10}$ predicted & $40.5 \pm 33.8$ & $46.4 \pm 27.4$ \\
\hline $\mathrm{MB}\left(\mu \mathrm{g} / \mathrm{m}^{3}\right)$ & -67.1 & -63.3 \\
\hline $\mathrm{MNB}(\%)$ & -62.2 & -57.5 \\
\hline $\mathrm{MGE}\left(\mu \mathrm{g} / \mathrm{m}^{3}\right)$ & 61.7 & 64.2 \\
\hline $\mathrm{MNGE}(\%)$ & 62.4 & 55.6 \\
\hline RMSE $\left(\mu \mathrm{g} / \mathrm{m}^{3}\right)$ & 84.9 & 77.6 \\
\hline
\end{tabular}


Fig. 2 shows the $\mathrm{PM}_{10}$ concentration simulated in the MALC, which is average for the month of February 2018. An of maximum $\mathrm{PM}_{10}$ concentration predicted by the model is noted in northern Lima, whose values vary from 55 to 60 However, there is a small area with a maximum value of $\mathrm{PM}_{10}$ (greater than $60 \mu \mathrm{g} / \mathrm{m}^{3}$ ) located at the intersection of three districts as mentioned here: (i) east of the Puente Piedra district; (ii) west of the Carabayllo district; and (iii) north of the Comas district (Fig. 2). In downtown MALC, the simulated $\mathrm{PM}_{10}$ concentration ranges from 20 to $35 \mu \mathrm{g} / \mathrm{m}^{3}$. Meanwhile, in the eastern MALC, the $\mathrm{PM}_{10}$ concentration predicted varies from 25 to $55 \mu \mathrm{g} / \mathrm{m}^{3}$ (Fig. 2).

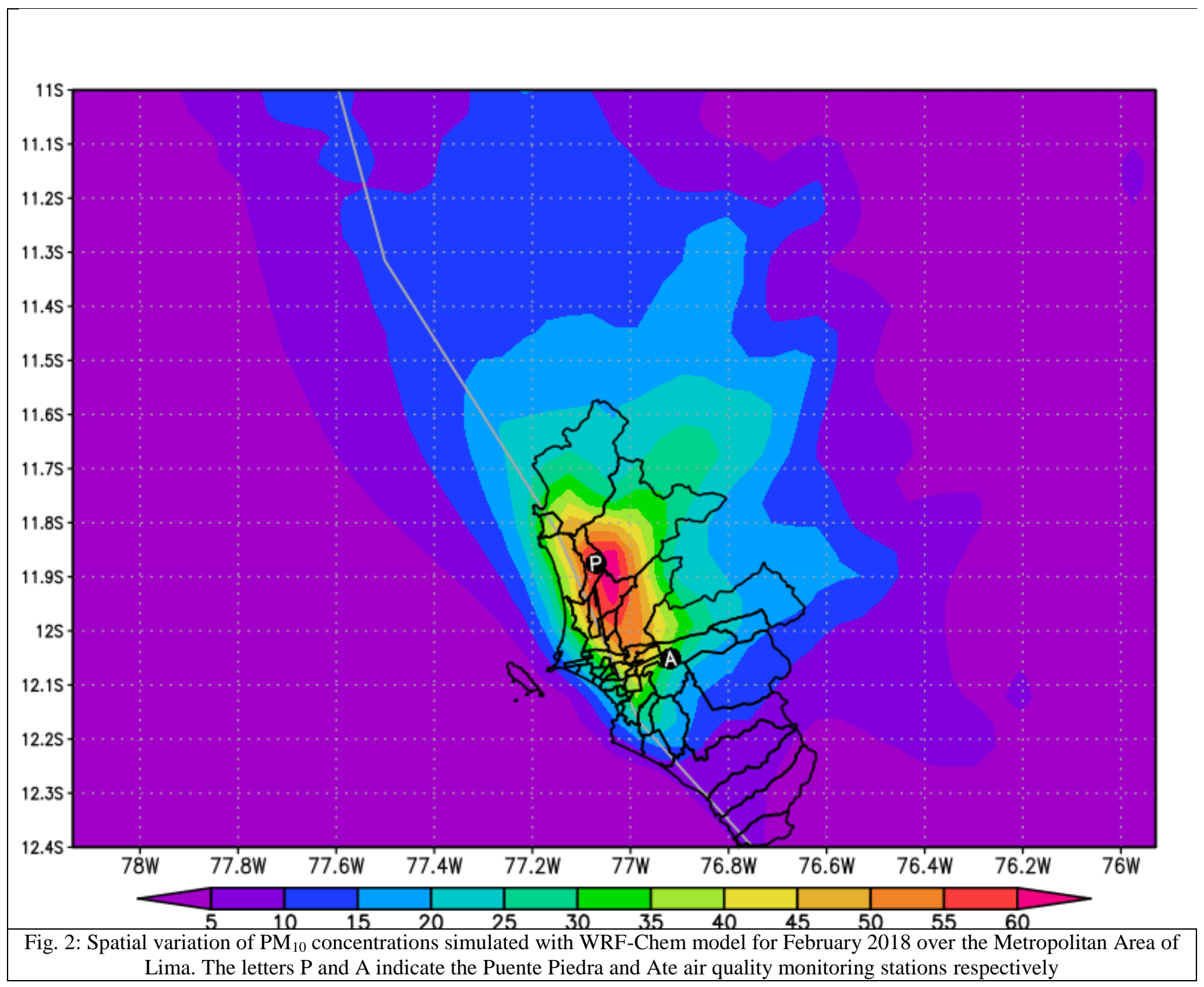




\section{Conclusion}

In this study, numerical simulations were performed in the MALC in February 2018 using the WRF-Chem (version 4.0) 4.0) model to simulate the hourly $\mathrm{PM}_{10}$ concentration and evaluate the model performance. First, the model performance on on $\mathrm{PM}_{10}$ concentrations was calculated using in-situ observations at two traffic air quality monitoring stations named Ate Ate and Puente Piedra. In general, WRF-Chem model output reasonably captured the temporal variations of PM 10 concentrations. However, the $\mathrm{PM}_{10}$ concentrations predicted were under-simulated by the model.

\section{Acknowledgements}

This research was supported under the CONCYTEC/FONDECYT contract 424-2019-FONDECYT with the Universidad Nacional Tecnológica de Lima Sur.

\section{References}

[1] Kong, Y., Sheng, L., Li, Y., Zhang, W., Zhou, Y., Wang, W., Zhao, Y., "Improving PM2.5 forecast during haze episodes over China based on a coupled 4D-LETKF and WRF-Chem system" Atmospheric Research, 2021, vol. 249, no. July, pp. 105366.

[2] Grell, G. A., Peckham, S. E., Schmitz, R., McKeen, S. A., Frost, G., Skamarock, W. C., Eder, B., "Fully coupled 'online' chemistry within the WRF model” Atmospheric Environment, 2005, vol. 39, no. 37, pp. 6957-6975.

[3] Zhou, G., Yu, Z., Qu, Y., "Real-time numerical source apportionment of PM2.5 concentrations over the Yangtze River Delta region, China," Atmospheric Environment, 2021, vol. 246, no. May, pp. 118104.

[4] Sánchez-Ccoyllo, O. R., Ordoñez-Aquino, C. G., Muñoz, Á. G., Llacza, A., Andrade, M. F., Liu, Y., ReáteguiRomero, W., Brasseur, G., "Modeling Study of the Particulate Matter in Lima with the WRF-Chem Model: Case Study of April 2016" International Journal of Applied Engineering Research, 2018, vol. 13, no. 11, pp. 10129.

[5] Balzarini, A., Pirovano, G., Honzak, L., Žabkar, R., Curci, G., Forkel, R., Hirtl, M., San José, R., Tuccella, P., Grell, G. A., "WRF-Chem model sensitivity to chemical mechanisms choice in reconstructing aerosol optical properties" Atmospheric Environment, 2015, vol. 115, pp. 604-619.

[6] Stockwell, W. R., Middleton, P., Chang, J. S., Tang, X., "The second generation regional acid deposition model chemical mechanism for regional air quality modeling" Journal of Geophysical Research, 1990, vol. 95, no. D10, pp. $16343-16367$.

[7] Andrade, M., Ynoue, R., Freitas, E. D., Todesco, E., Vela, A. V., Ibarra, S., Martins, L. D., Martins, J. A., Carvalho, V. S. B., "Air quality forecasting system for Southeastern Brazil," Frontiers in Environmental Science, 2015, vol. 3, no. FEB, pp.1-14

[8] Wang, X., Li, L., Gong, K., Mao, J., Hu, J., Li, J., Liu, Z., Liao, H., Qiu, W., Yu, Y., Dong, H., Guo, S., Hu, M., Zeng, L., Zhang, Y., "Modelling air quality during the EXPLORE-YRD campaign - Part I. Model performance evaluation and impacts of meteorological inputs and grid resolutions" Atmospheric Environment, 2021, vol. 246, no. December, pp. 118131. 